\title{
Prophylactic use of antibiotic for incomplete and missed miscarriage, prior to medical and surgical management: a randomized controlled trial
}

\author{
D P G G M Prasanga ${ }^{a}$, C Rathnayaka ${ }^{b}$, S N M P K Gunathilaka ${ }^{c}$, C Kandauda $^{b}$, M A M Jayawardana
}

\begin{abstract}
Introduction: Miscarriage is a common gynaecological problem in day to day practice. Post miscarriage care is a challenging area coming under reproductive health. Prevention of pelvic sepsis is a main component. Effective antibiotic prophylaxis at the time of treatment for incomplete and missed miscarriage may be the answer for it. But in current practice, there is conflicting evidence and no clear guidance for the necessity of antibiotic prophylaxis.

Objective: To determine the effectiveness of prophylactic doxycycline use, prior to surgical and medical evacuation of incomplete and missed miscarriage, in view of reducing the post-procedure pelvic infections.

Method: Three hundred and ninety four patients were randomized into two groups. One group $(\mathrm{n}=200)$ received $200 \mathrm{mg}$ doxycycline single dose and the other group $(n=194)$ received placebo single dose, one hour prior to the medical and surgical management. Post procedure pelvic infection was assessed by five clinical parameters within three days and two weeks later. SPSS used for the data analysis.

Result: There were no statistically significant differences in the age, parity, number of children and gestational age in between the doxycycline and placebo groups. Post intervention pelvic infection was diagnosed $4 \%$ in the doxycycline group and $6.18 \%$ in the placebo group within three days, which was not statistically significant $(\mathrm{P}=0.367)$. It was $4.5 \%$ and $8.7 \%$ for doxycycline and placebo treated groups respectively at two weeks. It was also not clinically significant $(P=0.104)$. There was no statistically significant difference in the type of miscarriage or the type of interventions in between the two groups.

Conclusion: The study revealed that single dose doxycycline prophylaxis prior to medical and surgical management of miscarriage was not able to achieve a statistically significant reduction in post intervention pelvic infection.
\end{abstract}

Key words: incomplete miscarriage, missed miscarriage, medical management, surgical management doxycycline, pelvic infection

Sri Lanka Journal of Obstetrics and Gynaecology 2021; 43: 84-91

DOI: http://doi.org/10.4038/sljog.v43i2.8000

a Senior Obstetrics and Gynaecology Registrar, WH Sunshine Hospital, Melbourne, Australia.

${ }^{\mathrm{b}}$ Consultant Obstetrician and Gynaecologist, Teaching Hospital, Peradeniya, Sri Lanka.

c Obstetrics and Gynaecology Registrar, Hervey Bay Hospital, Queensland, Australia.

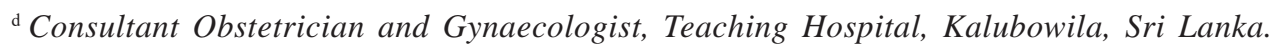

Correspondence: DPGGMP, e-mail: prasangagayan@yahoo.com

https://orcid.org/0000-0002-3338-2864

Received $13^{\text {th }}$ February 2021

Accepted $1^{\text {st }}$ June 2021

This is an open-access article distributed under the terms of the Creative Commons Attribution 4.0 International License, which permits unrestricted use, distribution and reproduction in any medium provided the original author and source are credited. 


\section{Introduction}

Reproductive health is a human right and a universal need especially for women, because of their physiological capability of reproduction. Post miscarriage care is a challenging area recognized as a part of reproductive health service to answer the complications of miscarriage ${ }^{1}$.

Miscarriage is defined as, loss of a pregnancy prior to achieve the viability, either by spontaneous or induced. Legally accepted gestational age (GA) of viability is 24 weeks ${ }^{2,3}$. Pregnancy loss prior to 24 weeks is considered as a miscarriage and beyond this considered as a still birth. In Sri Lanka viability is considered from 28 weeks of gestation.

About 10\%-20\% clinical pregnancies are end up as a miscarriage. ${ }^{4}$ The rate of clinical pregnancy loss is known to be decreased with the gestational age, $50 \%$ at four weeks, $25 \%$ at five to six weeks and $2 \%$ after fourteen weeks. ${ }^{5}$

Incomplete miscarriage is defined as, persistence of products of conception within the uterine cavity ${ }^{5}$ Intra uterine gestational sac with a diameter of more than $25 \mathrm{~mm}$ without a fetus or a fetal pole with a crown rump length more than $7 \mathrm{~mm}$ without a heartbeat is defined as missed miscarriage ${ }^{6}$.

Management of incomplete or missed miscarriage can be expectant, medical or surgical depending on the clinical situation and the preference of the women. Prostaglandins are used for the medical management, either by vaginally or orally, with or without anti progestogens. Evacuation of retained products of conception (ERPC) or dilatation and evacuation (D\&E) are considered as surgical management.

Currently, most of the gynecological units are practicing combination of medical and surgical techniques. Though, surgical management has shown a higher success rate $(95-100 \%),{ }^{2}$ it has multiple complications compared to the medical management. Trauma to cervix, uterine perforation and postoperative infections (endometritis, PID) are some of the short term complications. Cervical incompetence, Asherman syndrome are some of the long term complications. Heavy bleeding, pain, pelvic infections and prolong hospital stay are some of the complications of medical management.
Prevention of pelvic sepsis is the main component of post miscarriage care. Effective antibiotic prophylaxis may be the answer to prevent post miscarriage pelvic infections and subsequent complications.

There is no consensus regarding antibiotic usage as a prophylaxis. Routine use of antibiotic prophylaxis is accepted in some medical units. But others, antibiotics usage is accepted only with the evidence of infection? Treating with antibiotics in septic abortion is well recognized fact in literature. Use of broad spectrum antibiotics in early uterine evacuation had shown a reduction in morbidity and mortality of septic abortion. Most of the past studies had been carried out for surgically induced miscarriage. There are very little studies on routine use of antibiotics as prophylaxis on medical or surgical management of incomplete or missed miscarriage. ${ }^{9}$

Most of the available evidences are not applicable to South Asian population, because they are from developed countries, where the prevalence of vaginal infections and PID is disimilar to South Asian population. ${ }^{10}$ The available evidences are insufficient to recommend or abandon the routine practice of antibiotic prophylaxis in the management of miscarriage,

This gray area needs more attention, because it involves large number of women who seek medical care in day to day practice. Therefore, this study was carried to assess the effectiveness of prophylaxis antibiotic as a single dose at the time of surgical as well as medical management of incomplete and missed miscarriage.

\section{Methodology}

This study was a double blind randomized controlled trial, carried out at the Professorial Gynaecology Unit, Teaching Hospital Peradeniya, Sri Lanka. Ethical approval was obtained from the Ethical Review Committee, Faculty of Medicine, University of Peradeniya. Study was registered at Sri Lanka Clinical Trial Registry.

Incomplete miscarriage was considered as products of conception thickness $>1.5 \mathrm{~cm}$ in trans-vaginal scan and missed miscarriage as intra uterine gestational sac diameter $>25 \mathrm{~mm}$ without a fetal pole or a fetal pole $>7 \mathrm{~mm}$ without heart beat on trans vaginal scan. 


\section{Flow chart of the study}

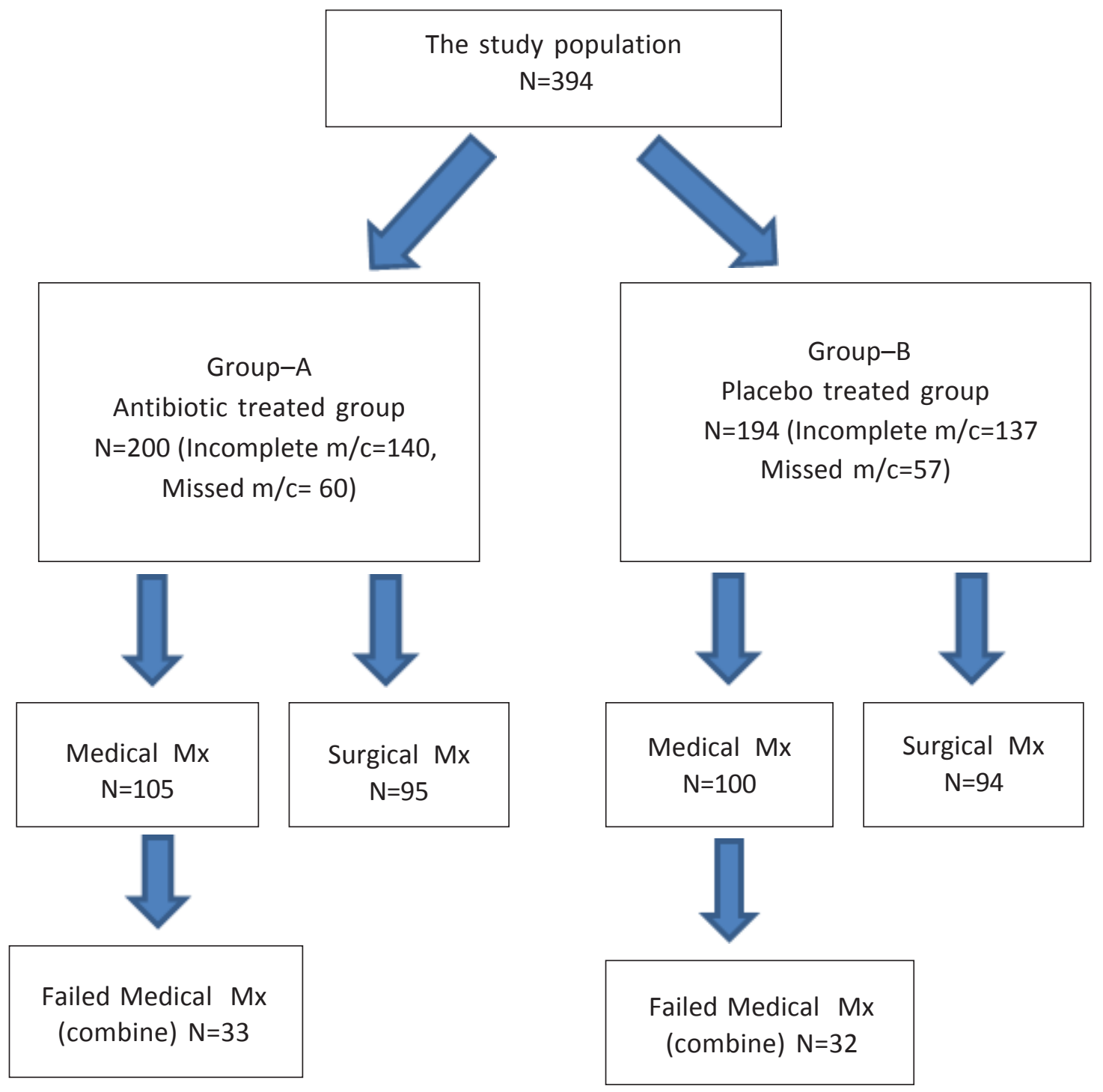

\section{Inclusion criteria:}

- All Women with incomplete or missed miscarriage, who are not having symptoms and signs of infection (as mentioned below in exclusion criteria).

- Pregnancy loss up to twenty weeks of gestation.

\section{Exclusion criteria were as follows:}

1. Women with signs and symptoms of infection as stated below
- Temperature $>37^{\circ} \mathrm{C}$

- Severe lower abdominal tenderness

- Smelly vaginal discharge

- Cervical motion tenderness / adnexal tenderness

\section{Allergy to doxycycline}

Study subjects were allocated into two groups by randomization using computer generated random numbers. Those with odd numbers had antibiotics. 
While others with even numbers had placebo. Sequentially numbered, sealed opaque envelops were packed with antibiotics or placebo according to the computer generated order. Within each arm subjects were randomly allocated to medical or surgical management. Failed medical management proceeded to surgical management in both arms, considered as combine management.

Group A subjects received a prophylactic single dose oral doxycycline $200 \mathrm{mg}$ one hour prior to the medical or surgical intervention. Group B subjects received placebo capsule (identical appearance and size as same as the doxycycline) as same as the group A.

Clinical signs of infection were measured before discharge from the unit, and two weeks later by a third person at gynaecology clinic, who also blinded for the intervention (Senior Medical Officer).

Five parameters were measured.

1. History: fever, lower abdominal pain, smelly vaginal discharge

2. Temperature $>37^{\circ} \mathrm{C}$.

3. Lower abdominal tenderness.

4. Positive cervical motion test with or without adnexal tenderness.

5. Presence of smelly vaginal discharge.

Presence of at least 3 out of 5 above parameters were taken as a clinical pelvic infection.

Statistical analysis was carried out using the Statistical Package for the Social Sciences (SPSS) version 20. As the data was normally distributed the Student's t-test and the Chi-squared test were used to compare means and proportions. $\mathrm{P}<0.05$ considered as statistically significant.

A total of three hundred and ninety-four women were recruited to the study (incomplete (277), missed miscarriage (117). They were randomized into doxycycline treating group (A) and placebo treating group (B), as 200 and 194 respectively by computer generated random numbers.

\section{Results}

There were no statistically significant differences in age, parity, number of children and POG in between the two groups (Table 1).

The percentage distribution of incomplete and missed miscarriage in group A and B were in similar pattern. The P-value was 0.438 . There was no statistically significant difference in the distribution of miscarriage types in the two groups.

There were 277 subjects with incomplete miscarriage randomly allocated into group A and B as 140 and 137 respectively. There was no statistically significant difference in type of intervention (medical, surgical or combine) within the incomplete miscarriage group in between the group A and B. $(\mathrm{P}$-value $=0.124)$

Hundred and seventeen women with missed miscarriage were randomized to group A and B, as 60 and 57 respectively. There was no statistically significant difference in type of interventions within missed miscarriage subjects in the group $\mathrm{A}$ and $\mathrm{B}$ (P-value was 0.325 ).

Table 1. Basic characteristics of group A and B. Age, parity, number of children, POA

\begin{tabular}{|l|l|l|c|}
\hline & $\begin{array}{c}\text { Group-A } \\
\text { N= 200 }\end{array}$ & $\begin{array}{c}\text { Group-B } \\
\text { N=194 }\end{array}$ & P-Value \\
\hline Age (y) - Mean (SD) & $29.9(6.885)$ & $30.1(7.215)$ & 0.8 \\
Parity - Mean (SD) & $02(01)$ & $02(1)$ & 0.8 \\
Number of children - & $01(01)$ & $01(01)$ & 0.9 \\
Mean (SD) & $73(18)$ & $70(18)$ & 0.1 \\
POA (days) - Mean (SD) & & & \\
\hline
\end{tabular}


The distribution of type of intervention showed similar pattern in between the two groups. 140, 189 and 65 women were managed medically, surgically and combine effort (failed medical management followed by surgical management) in two groups respectively. There was no statistically significant difference in type of interventions in between the doxycycline and placebo group. P-value was 0.47 .

Hundred and forty women were managed by medical interventions, from that 72 were in the doxycycline treated group and 68 were in the placebo group. The distribution of incomplete and missed miscarriage within the medically managed women in the two groups were not statistically significant. The P-value was 0.635 .

Hundred and eighty nine women were managed surgically as 95 and 94 in GroupA and B respectively. There was no statistically significant difference in distribution of type of miscarriages within surgically managed women in this two groups. $(\mathrm{P}-\mathrm{value}=0.29)$

Sixty five women who had failed medical management followed by surgical evacuation (combine management) including 33 and 32 respectively in GroupA and B. The distribution of type of miscarriage in this group was in similar pattern. The P-value was 0.205 . Therefore, there was no statistically significant difference in type of miscarriage when combine management was done.

Presence of at least three out of five clinical parameters was considered as pelvic infection. Pelvic infection was diagnosed $4 \%$ in the group $\mathrm{A}$ and $6.18 \%$ in the group B within three days. The P-value was 0.367 . OR and 95\% Confidence Interval was 0.6 (0.25-1.58). There was no statistically significant difference of post intervention pelvic infection rate in between prophylactic doxycycline and placebo given groups within three days of duration (Table $2 \& 3$ ).

Table 2. Post intervention pelvic infection within three days

\begin{tabular}{|l|c|c|c|c|c|}
\hline Pelvic infection & $\begin{array}{c}\text { Group-A } \\
\text { N=200 (\%) }\end{array}$ & $\begin{array}{c}\text { Group- B } \\
\text { N=194 (\%) }\end{array}$ & $\begin{array}{c}\text { Total } \\
\text { N=394 }\end{array}$ & OR (95\% CI) & P-value \\
\hline Present & $08(04 \%)$ & $12(6.18 \%)$ & 20 & $0.6(0.25-1.58)$ & 0.367 \\
Absent & $192(96 \%)$ & $182(94 \%)$ & 374 & & \\
\hline
\end{tabular}

Table 3. Post intervention pelvic infection within two weeks

\begin{tabular}{|l|c|c|c|c|c|}
\hline Pelvic infection & $\begin{array}{c}\text { Group-A } \\
\text { N=200 (\%) }\end{array}$ & $\begin{array}{c}\text { Group- B } \\
\mathbf{N = 1 9 4}(\mathbf{\%})\end{array}$ & $\begin{array}{c}\text { Total } \\
\mathbf{N = 3 9 4}\end{array}$ & OR (95\% CI) & P-value \\
\hline Present & $09(4.5 \%)$ & $17(8.7 \%)$ & 26 & $0.48(0.21-1.10)$ & 0.104 \\
Absent & $184(92 \%)$ & $168(86.5 \%)$ & 352 & & \\
Unknown & $07(3.5 \%)$ & $09(4.8 \%)$ & 16 & & \\
\hline
\end{tabular}


Sixteen women were lost to follow up (4.06\%). Seven patients in the doxycycline group (1.77\%) and nine patients in the placebo group (2.28\%). Therefore, the presence of pelvic infection was not known to them. Twenty patients who had pelvic infection within three days, in the group A (08) and group B (12), treated with antibiotics. Newly diagnosed pelvic infections at two-week assessment (after discharged from the hospital) plus earlier diagnosed pelvic infection within three days of hospital stay, was considered as total pelvic infections within two weeks. Therefore, total pelvic infections within two-week were 9 (4.5\%) and $17(8.7 \%)$ respectively in group $\mathrm{A}$ and $\mathrm{B}$. The P-value was 0.104 . OR and $95 \%$ CI was 0.48 (0.21-1.10).

There was no statistically significant difference of post intervention pelvic infection in between doxycycline and placebo group within two weeks.

The prevalence of pelvic infection for the entire study group was $6.59 \%(26 / 394)$. It was for the doxycycline treatment group 4.5\% (9/200) and for the placebo group $8.7 \%$ (17/194). The difference was $4.2 \%$.

Out of 277 incomplete miscarriage women, 15 had pelvic infections in the study population as $07(05 \%)$ and $08(5.8 \%)$ respectively in the groupA and $\mathrm{B}$, within three days. The P-Value was 0.79 .

It was $08(5.7 \%)$ and $11(08 \%)$ for group $\mathrm{A}$ and B respectively within two weeks. The P-Value was 0.48 . There was no statistically significant difference in view of pelvic infection in the incomplete miscarriage subjects in group A and B within three days or two weeks (Table 4 \& 5).

The pelvic infection in missed miscarriage group within three days was $01(1.6 \%)$ and $04(07 \%)$ in the group $\mathrm{A}$ and $\mathrm{B}$. The P-value was 0.20 . It was for within two weeks $01(1.6 \%)$ and $06(10 \%)$ respectively for group $\mathrm{A}$ and B. The P-value was 0.06 for that. Therefore, there was no statistically significant difference in pelvianfection in the group ofmissed miscarriage subjects in group $\mathrm{A}$ and $\mathrm{B}$, respectively in three days and two weeks.

Table 4. Comparison of pelvic infection in the mode of intervention groups within 3 days

\begin{tabular}{|c|c|c|c|c|c|c|c|}
\hline \multirow{3}{*}{$\begin{array}{l}\text { Intervention } \\
\text { Group }\end{array}$} & \multirow{2}{*}{\multicolumn{2}{|c|}{$\begin{array}{c}\text { Group-A } \\
\text { Pelvic infection }\end{array}$}} & \multirow[b]{3}{*}{$\begin{array}{c}\text { Total } \\
\mathbf{N}=\mathbf{2 0 0}\end{array}$} & \multirow{2}{*}{\multicolumn{2}{|c|}{$\begin{array}{c}\text { Group-B } \\
\text { Pelvic infection }\end{array}$}} & \multirow[b]{3}{*}{$\begin{array}{c}\text { Total } \\
\mathrm{N}=194\end{array}$} & \multirow{3}{*}{ P-value } \\
\hline & & & & & & & \\
\hline & $\begin{array}{c}\text { Present } \\
\mathrm{N}=08\end{array}$ & $\begin{array}{c}\text { Absent } \\
\mathrm{N}=192\end{array}$ & & $\begin{array}{c}\text { Present } \\
\mathrm{N}=12\end{array}$ & $\begin{array}{c}\text { Absent } \\
\mathrm{N}=182\end{array}$ & & \\
\hline Medical & $2(2.7 \%)$ & $70(97.3 \%)$ & 72 & $3(4.4 \%)$ & $65(95.6 \%)$ & 68 & 0.67 \\
\hline Surgical & $3(3 \%)$ & 92 (97\%) & 95 & $5(5.3 \%)$ & $89(94.7 \%)$ & 94 & 0.50 \\
\hline Combine & $3(09 \%)$ & $30(91 \%)$ & 33 & $4(12.5 \%)$ & $28(87.5 \%)$ & 32 & 0.70 \\
\hline
\end{tabular}

Table 5. Comparison of pelvic infection in the mode of intervention groups within two weeks

\begin{tabular}{|l|ccc|ccc|}
\hline Pelvic infection & \multicolumn{3}{|c|}{ Group-A } & \multicolumn{3}{c|}{ Group-B } \\
& $\begin{array}{c}\text { Medical } \\
\text { N=72 (\%) }\end{array}$ & $\begin{array}{c}\text { Surgical } \\
\text { N=95 (\%) }\end{array}$ & $\begin{array}{c}\text { Combine } \\
\text { N=33 (\%) }\end{array}$ & $\begin{array}{c}\text { Medical } \\
\text { N=68 (\%) }\end{array}$ & $\begin{array}{c}\text { Surgical } \\
\text { N=94 (\%) }\end{array}$ & $\begin{array}{c}\text { Combine } \\
\text { N=32 (\%) }\end{array}$ \\
\hline Present & $02(2.7)$ & $04(4)$ & $03(9)$ & $04(5.8)$ & $06(6)$ & $07(21)$ \\
Absent & $66(91.6)$ & $89(93)$ & $29(87)$ & $62(91)$ & $84(89)$ & $22(68)$ \\
Unknown & $04(5.7)$ & $02(3)$ & $01(4)$ & $02(3.2)$ & $04(5)$ & $03(9)$ \\
\hline
\end{tabular}




\section{Discussion}

Pelvic infections need to be considered in women who are undergoing medical or surgical management of miscarriage. The patho-physiology of pelvic infection involves, ascending of organisms like Neisseria gonorrhea, Chlamydia trachomatis and other mixed aerobes, anaerobes from lower genital tract to upper genital tract. In the procedures like ERPC protective cervical barrier is compromised and the curette may act as a vehicle for introducing infections from vagina to uterine cavity. The open cervix seen in incomplete miscarriage may also facilitate the ascend of infection from the vagina to the uterine cavityThere are identified risk factors associate with increased risk of pelvic infections following active management of miscarriages $^{11,19}$ multiple sexual partners, previous PID, nulliparity and age $<20$ years are some of them.

Numerous studies have shown antibiotic prophylaxis at the time of suction curettage of induced first trimester miscarriages can significantly reduce the pelvic infections specially in high risk women ${ }^{11,12,13,14}$. Some studies recommended antibiotics, prior to surgical evacuation $^{12,13}$. While others have advocated their use on women with a high risk of infection ${ }^{4,15,16}$. But some authors do not recommend prophylactic antibiotics for management of the miscarriages ${ }^{17}$.

In our study there was no statistically significant difference considering the age, parity, POA, number of children in between the two groups. There was no statistically significant difference in type of miscarriage (incomplete or missed) and type of interventions carried out (surgical, medical or combine) in between two groups.

Pelvic infection was diagnosed $04 \%$ in the group A and $6.18 \%$ in the group B within three days. The P-value was 0.36 . Diagnosis of pelvic infection at twoweek time was $4.5 \%$ and $8.7 \%$ respectively for group $\mathrm{A}$ and B. The P-value was 0.11 . Therefore, there was no statistically significant difference found in pelvic infections between doxycycline treated and placebo treated groups within three days and in two-week duration.

The rates of pelvic infections byChlamydia trachomatis and Neisseria gonorrhea has geographical variations, ranging from $5 \%$ to $20 \%{ }^{13,15}$. Prevalence of chla- mydia, gonorrhea in Sri Lanka was found as 8.2\%, $7.6 \%$ and Trichomonas vaginalis as $2.3 \%$ in clinic setting ${ }^{20}$. Therefore, doxycycline was selected as the prophylaxis for this study. It was selected instead of azithromycin because it was inexpensive, easily tolerable and effective for common pathogenic organisms causing PID. Previous studies also showed the use of oral doxycycline was effective in reducing post abortion sepsis relative to placebo ${ }^{11,13,18,21}$. North American Abortion Federation found that doxycycline is the routinely used antibiotic prophylaxis in $91 \%$ for the miscarriages $^{22}$. In our study we used single dose of doxycycline $200 \mathrm{mg}$ orally prior to interventions because of the compliance issues. We did not perform the vaginal swab cultures to identify pathogenic organisms. So, we missed the chance of identifying the causative pathogenic organisms and its' prevalence.

\section{Conclusion}

This study revealed, prophylactic single dose of doxycycline $200 \mathrm{mg}$ was unable to achieve a statistically significant reduction in pelvic infection, post medical or surgical management of incomplete and missed miscarriage.

\section{Limitations}

1) Pelvic infection was assessed by only using clinical parameters (symptoms and signs). Some of the symptoms assessed by the history were not much reliable because of subjective variations in the presentation of history like fever, lower abdominal pain, smelly vaginal discharge. Some may had exaggerated symptoms and some may have ignored them. But the clinical signs were more reliable compare to history parameters.

2) Pre and post procedural microbiological isolation of pathogenic organisms from genital tract were not performed to determine the exact pelvic infection.

\section{Acknowledgements}

I would like to thank all the patients who participated in the study to make this event a success. My special thanks to Dr. Chathura Rathnayake, and all the staf $\mathrm{f}$ of Gynaecology Professorial Unit, Teaching Hospital Peradeniya, Sri Lanka. 


\section{References}

1. World Health Organization. Complications of abortion: technical and managerial guidelines for prevention and treatment. Geneva. World Health Organisation: 1995.

2. Luesley DM, Baker PN. Obstetrics and Gynaecology. An evidence based text for MRCOG, 2nd Ed, London, Arnold. 2010; 57: 653-6.

3. Royal College of Obstetricians and Gynaecologists. Greentop guideline NO.25,OCT 2006. Available at htpp;www.rcog.org.uk

4. Alberman E, Stabile S, Grudzinkas G, Chard T. Spontaneous Abortion: Diagnosis and Treatment. London, Springer-Verlag. 1992; 9-20.

5. Cambell S, Monga A. Gynaecology by Ten Teachers, 17th Ed, London,Arnold. 2000; 8: 102106.

6. Doubilet PM, Bourne T, Blaivas M. Diagnostic criteria for nonviable pregnancy in the first trimester. N Engl J Med 2013; 369: 1443-51.

7. May W, Gulmezoglu AM, Ba-Thike K.Antibiotics for incomplete abortion (Review). Cochrane Database of systemic review 2007, Issue 4. Art No.:CD001779.DOI:10.1002/14651858. CD001779.pub2.

8. Chow AW, Marshall, JR, Guze LB.A double-blind comparison of clindamycin with penicillin plus chloramphenicol in treatment of septic abortion. $\mathrm{J}$ Infect Dis 1977; 135(Suppl): S35-9.

9. Pattinson RC.Antibiotics for incomplete abortion: RHL Commentary (last revised: 24th June 2002) The WHO Reproductive Health Library; Geneva: World Health Organization.

10. Mangalika GK, Cankannamge SK, Priyadarshana D, Shamini P, Sujatha M, Geeganage W, Nalaka A. Prevalence of Chlamydia trachomatis in women attending sexually transmitted disease clinics in the Colombo district, Sri Lanka.

11. Levallois P, Rioux JE. Prophylactic antibiotics for suction curettage abortion: Results of a clinical controlled trial. Am J Obstet Gynecol 1988; 158(1): 100-105.
12. Grimes DA, Schulz KF, Cates WJ. Prophylactic antibiotics for curettage abortion. Am J Obstet Gynecol 1984; 150: 689-94.

13. Darj E, Stralin EB, Nilsson S. The prophylactic effect of doxycycline on postoperative infection rate after first trimester abortion. Obstet Gynaecol 1987; 70(5): 755-8.

14. Heisterberg L. Prophylactic antibiotics in women with a history of pelvic inflammatory disease undergoing first trimester abortion. Acta Obstet Gynecol Scand 1987; 66: 15-18.

15. Sonne-Holm S, Heisterberg L, Hebjorn S, DyringAndersen K, Andersen JT, Hejl BL. Prophylactic antibiotic in first trimester abortions: A clinical controlled trial. Am J Obstet Gynecol 1982; 60(4): 502-5.

16. Hemsell DL. Prophylactic antibiotics in gynaecologic and obstetric surgery. Rev Infect Dis 1991; 13: 821-41.

17. Decenzo JA, Cavanaugh D. Management of incomplete abortion on an outpatient basis. Am J Obstet Gynecol 1967; 97: 17-20.

18. Brewer C. Prevention of infection after abortion with a supervised single dose of oral doxycycline. BMJ 1980; 281: 780-1.

19. Park N, Flock M, Schulz KF, Grimes DA. Preventing febrile complication of suction curettage abortion. Am J Obstet Gynecol 1985; 152: 252-5.

20. Sarawickrema N, Tabrizi S, Young E, Gunawardana P, Garland S. Prevalence ofTrichomonas vaginalis, Chlamydia trachomatis, Neisseria gonorrhea and human papilloma virus in a sexual health clinic setting in urban Sri Lanka. International Journal of STD \& AIDS. 2015; 26(10): 733-9.

21. London RS, London ED, Siegelbaum M, Goldstein P. Use of doxycycline in elective first trimester abortion. South Med J 1978; 71: 672-3.

22. Lichtenberg ES, Paul M, Jones H. First trimester surgical abortion practices: A survey of National Abortion Federation members. Contraception 2001; 64: 345-52. 